\title{
Numerical simulation for the drying shrinkage of autoclaved aerated concrete
}

\author{
J. Kočí ${ }^{1}$, J. Maděra ${ }^{1}$, T. Koudelka ${ }^{2}$, J. Kruis ${ }^{2} \&$ R. Černý ${ }^{1}$ \\ ${ }^{1}$ Department of Materials Engineering and Chemistry, \\ Faculty of Civil Engineering, Czech Technical University in Prague, \\ Czech Republic \\ ${ }^{2}$ Department of Mechanics, Faculty of Civil Engineering, \\ Czech Technical University in Prague, Czech Republic
}

\begin{abstract}
A mathematical model for the description of drying shrinkage of autoclaved aerated concrete (AAC) is presented, bringing together the hygrothermal and mechanical considerations. The verification of the model is done using an approximation of a real laboratory experiment. Then, the applicability of the model is demonstrated by a numerical simulation of drying shrinkage and wetting expansion of AAC under real weather data. The presented results showed that the model works precisely and the presumption was made to extend the model in subsequent research.
\end{abstract}

Keywords: autoclaved aerated concrete, drying shrinkage, volumetric changes, numerical simulation.

\section{Introduction}

Autoclaved aerated concrete (AAC) became a widely used building material in the last decades due to its favourable mechanical and thermal properties. A combination of these parameters together with a low price and environmental friendliness made this material popular among designers all over the world. However, using AAC in civil engineering also has some drawbacks, which must be taken into account during the designing process of any AAC construction. Improper design may lead to the formation of cracking of both internal and external finishes or even the AAC blocks themselves. Another typical failure is, for example, detachment of renders from AAC blocks, frost failure, cracks 
around windows, etc. In order to prevent these cracking failures, it is necessary to employ complex computational simulations of heat and moisture transport to identify weak points in the construction.

Most failures in the form of cracks have one common reason - volumetric changes. These changes occur in the material due to drying/wetting, temperature change or carbonation. Drying shrinkage presents the most important volumetric change during the lifetime of any AAC construction. First, the rate of drying shrinkage depends on the composition of AAC. It has been reported in [1] that drying shrinkage of AAC with only cement as a binder is significantly higher than that produced with lime or lime and cement. Knowledge of the proper composition of AAC is not enough, as long as there is still the common practice of designing AAC constructions that involves empirical processes. These processes usually either underestimate the risk of possible failures due to drying shrinkage, or are not powerful enough to reveal potential weakness. Even the national standard in the Czech Republic CSN EN 680-733 1356:2006 [2] underestimates the risks of possible damage by defining the conventional drying range of moisture content for estimation of drying shrinkage from $30 \%$ to $6 \%$ by mass. These thresholds represent the moisture content change from freshly produced $\mathrm{AAC}$ to the equilibrium moisture content in the AAC. It has been concluded in recent research [3] that drying shrinkage of different types of AAC is increasing with decreasing moisture content in the AAC pore system and this increase is fastest in the range of very low moisture, much lower than $6 \%$. This feature of the AAC drying process is commonly not considered by designers and may be responsible for surface cracking. One the other hand, in some research papers there already exist more sophisticated approaches for designing AAC constructions $[4,5]$, so far dealing with heat and moisture transport only.

In this paper, we present a hygro-thermo-mechanical model, which is used for the description of hygric expansion/shrinkage of AAC. This model is verified by approximation of a laboratory experiment for determination of drying shrinkage. Finally, the usage of verified model settings is demonstrated in the long-term simulation of hygric expansion/shrinkage of an AAC wall exposed to real weather data. The initial moisture content of the material is set differently, ranging from $30 \%$ to $6 \%$ by mass and thus describing the state of the material in different time intervals between its journey from the factory and construction on site.

\section{Materials}

The research was accomplished on commercial AAC $\mathrm{P} 2-400$ produced by $\mathrm{H}+\mathrm{H}$ Czech Republic, which is designed for use as load-bearing and non-bearing external and internal walls [6]. For the numerical simulations, the basic physical parameters were obtained, as well as moisture and heat transport and storage characteristics. All the results are summarized in Table 1 and Figs. 1 and 2 [7]. The following symbols are used in Table 1: $\rho$ - bulk density, $\psi$ - porosity, $c-$ specific heat capacity, $\mu$ - water vapour diffusion resistance factor, $\lambda$ - thermal conductivity and $w_{\text {hyg }}$ - hygroscopic moisture content by volume. 
Table 1: Basic material parameters of AAC.

\begin{tabular}{|l|l|}
\hline$\rho[\kappa \gamma / \mu 3]$ & 407 \\
\hline$\psi[\%]$ & 80.7 \\
\hline$\chi[\vartheta / \kappa \gamma \mathrm{K}]$ & 1210 \\
\hline$\mu \delta \rho \psi \chi \cup \pi[-]$ & 14.4 \\
\hline$\mu_{\text {wet cup }}[-]$ & 3.7 \\
\hline$\lambda_{\text {dry }}[\mathrm{W} / \mathrm{mK}]$ & 0.0927 \\
\hline$\lambda_{\text {sat }}[\mathrm{W} / \mathrm{mK}]$ & 0.385 \\
\hline$w_{\text {hyg }}\left[\mathrm{m}^{3} / \mathrm{m}^{3}\right]$ & 0.0186 \\
\hline
\end{tabular}

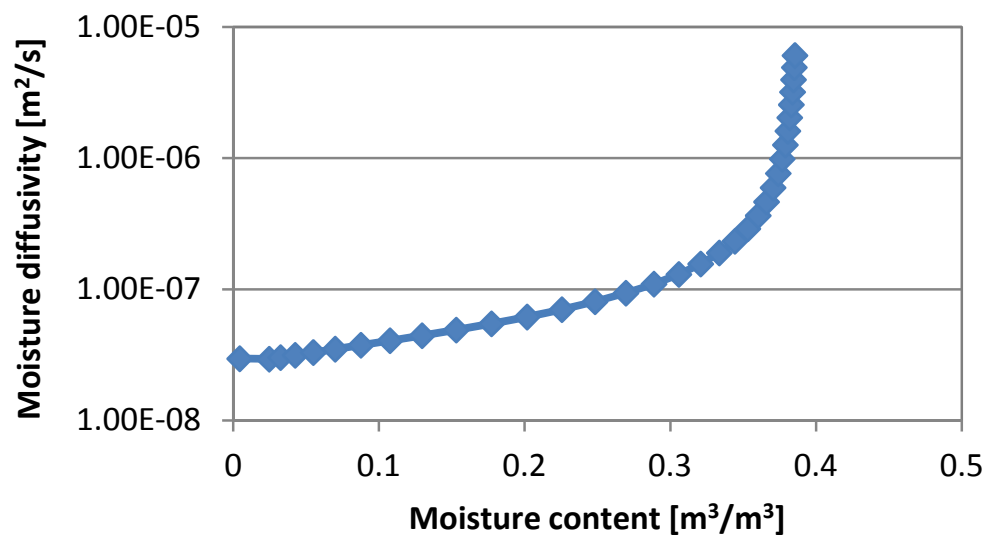

Figure 1: Moisture diffusivity as a function of moisture content.

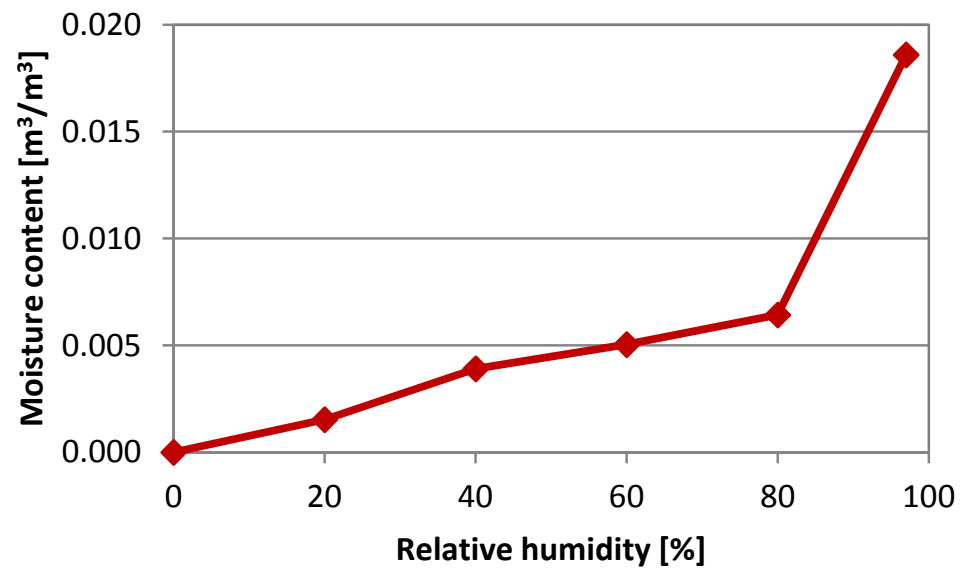

Figure 2: Adsorption isotherm. 
The drying shrinkage test was done on rod shaped samples with dimensions of $40 \times 40 \times 160 \mathrm{~mm}$ in accordance with ČSN EN 13009 [8]. Square gauge plugs were glued on both face sides of the specimen to facilitate length measurements. The experimental results are presented in [3], and partially in Fig. 3.

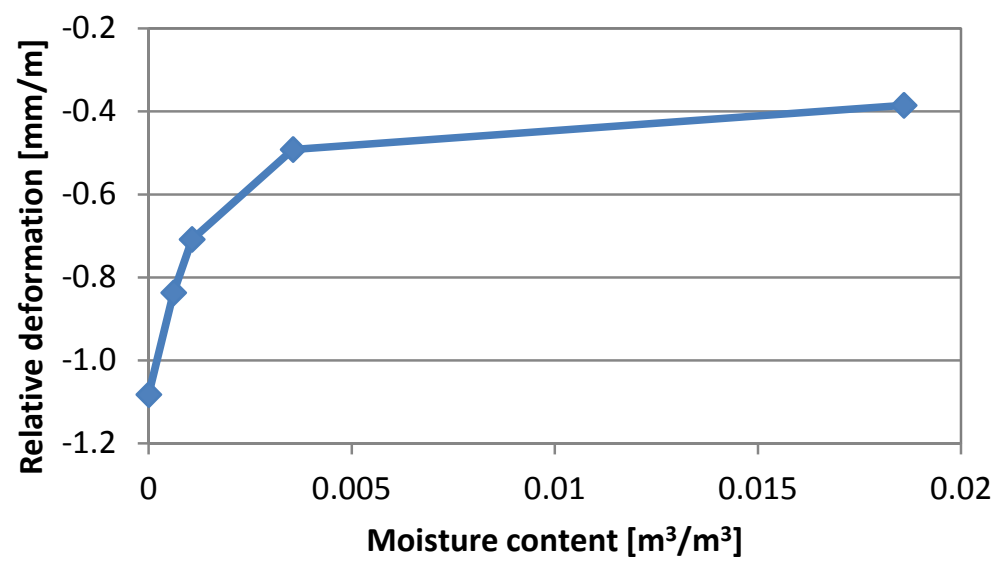

Figure 3: Drying shrinkage of AAC for hygroscopic range of moisture content.

\section{Mathematical model}

For the description of heat and moisture transport, Künzel's mathematical model was used [9]. Evolution of the shrinkage strain was described with the help of the approximation of measured data by appropriate function $g(w)$, which relates the shrinkage strain with volumetric moisture content $w$. The time increment of the shrinkage part of the strain tensor can be defined with regard to the volumetric changes due to shrinkage as follows:

$$
\boldsymbol{\varepsilon}_{s h}=\boldsymbol{\delta} \frac{d g}{d w} \dot{w}=\boldsymbol{\delta} \beta \dot{w}
$$

where $\delta$ is the Kronecker delta and $\beta$ is the hygric expansion coefficient. Taking into account the shrinkage effect, the increment of the stress tensor $\boldsymbol{\sigma}$ can be written as:

$$
\dot{\boldsymbol{\sigma}}=\mathbf{D}_{e l}:\left(\boldsymbol{\varepsilon}-\boldsymbol{\varepsilon}_{s h}\right),
$$

where $\mathbf{D}_{\mathrm{el}}$ is the fourth order elastic stiffness tensor and $\boldsymbol{\varepsilon}$ is the second order strain tensor.

The computational analysis was performed using the computer code HEMOT [10], which was developed at the Department of Materials Engineering and 
Chemistry, Faculty of Civil Engineering, Czech Technical University in Prague. It enables simulation of thermal and hygric behaviour of constructive building details in a 1-D or 2-D arrangement. The construction of the code is based on the application of a general finite element computer simulation tool, SIFEL (Simple Finite Elements) developed at the Department of Mechanics, Faculty of Civil Engineering, Czech Technical University in Prague [11].

\section{Numerical simulations and discussion}

The numerical simulations were accomplished in two steps. First, the mathematical model was calibrated and verified using experimental data from the drying shrinkage experiment. Then, the calibrated model was used for a demonstration of its applicability on real weather data. The scheme of the modelled construction is shown in Fig. 4.

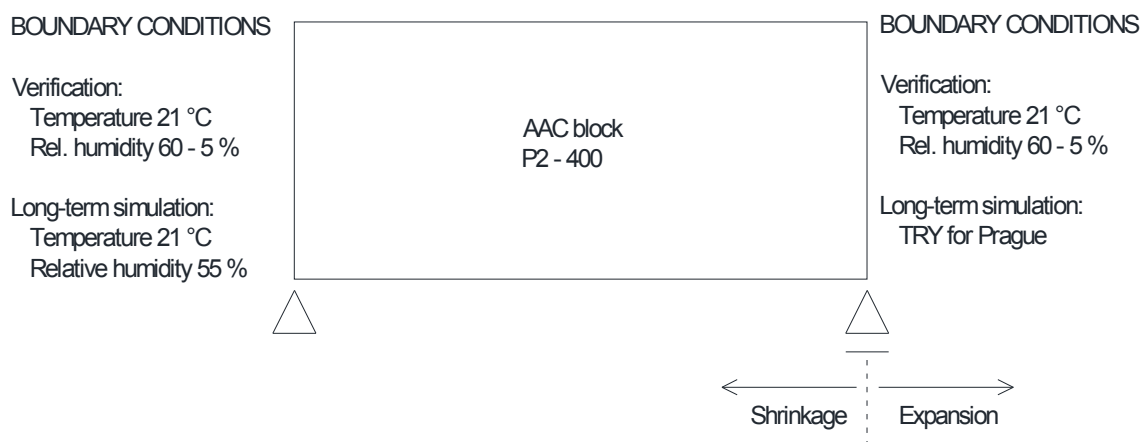

Figure 4: Scheme of modelled construction.

\subsection{Verification of the mathematical model}

The mathematical model used for determination of shrinkage strain requires hygric expansion coefficient $\beta$ as a function of moisture content $w$. To obtain this parameter, the experimental data shown in Fig. 3 were processed with a numerical tool DataSmoother [12], which enables either interpolation or the approximation (smoothing) of any experimental data by a set of consequential cubic spline functions. After the approximation of experimental data, the hygric expansion coefficient is calculated as a first derivative of the approximation function. The hygric expansion coefficient is shown in Fig. 5.

The verification of the model was done using several steady state numerical simulations with different boundary conditions, according to the real experiment. At the beginning of the experiment (or numerical simulation), the material was fully saturated and, then, the relative humidity of the surrounding air was kept at $60,40,20,8$ and $5 \%$. For each state of boundary conditions, the steady state of the material was reached and the drying shrinkage was determined. The result of the calibration process is shown in Fig. 6. The experimental data in Fig. 6 
were interpolated using DataSmoother software in order to obtain drying shrinkage as a function of moisture content $w$ in the range from 0 to $0.02 \mathrm{~m}^{3} / \mathrm{m}^{3}$. This makes the comparison between experimental and simulation data easier. It is obvious from that figure that the model is set up very precisely and it is possible to use it for the demonstration of hygric shrinkage/expansion under real weather data.

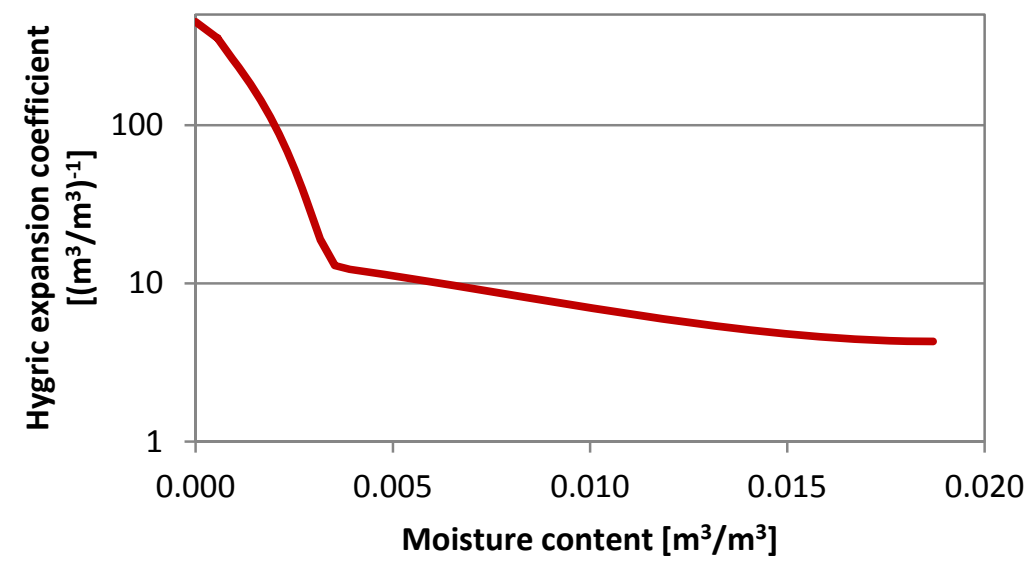

Figure 5: Hygric expansion coefficient as a function of moisture content.

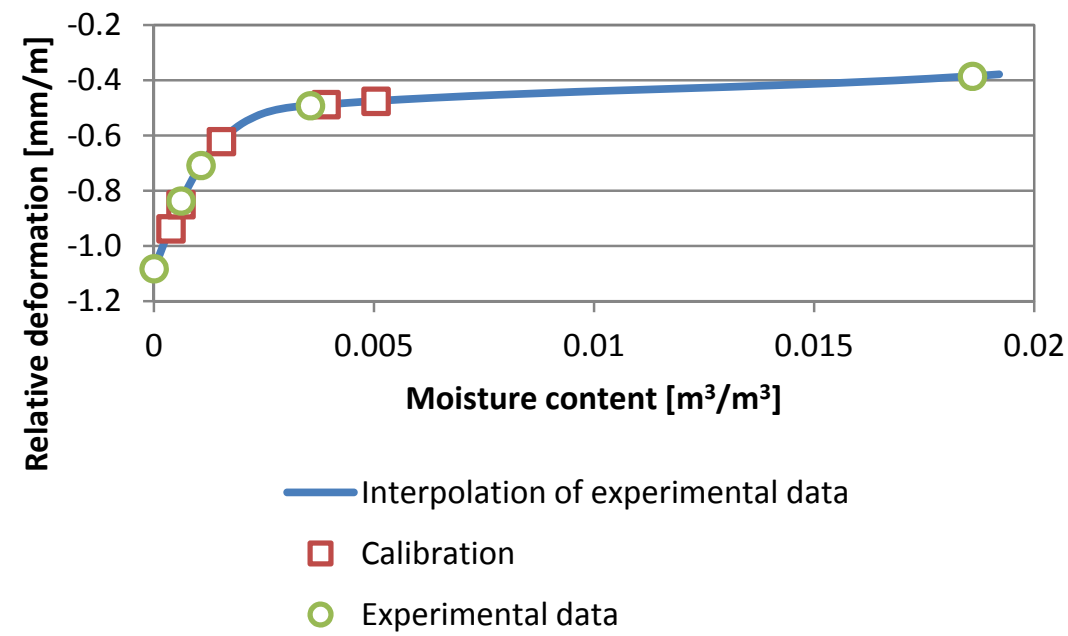

Figure 6: Verification of mathematical model. 


\subsection{Long-term simulation}

Long-term simulations were performed with three different initial states of moisture content $-30,20$ and $6 \%$ by mass. For the boundary condition the Test Reference Year (TRY) for Prague was used. The simulation results are summarized in Figs. 7 and 8.

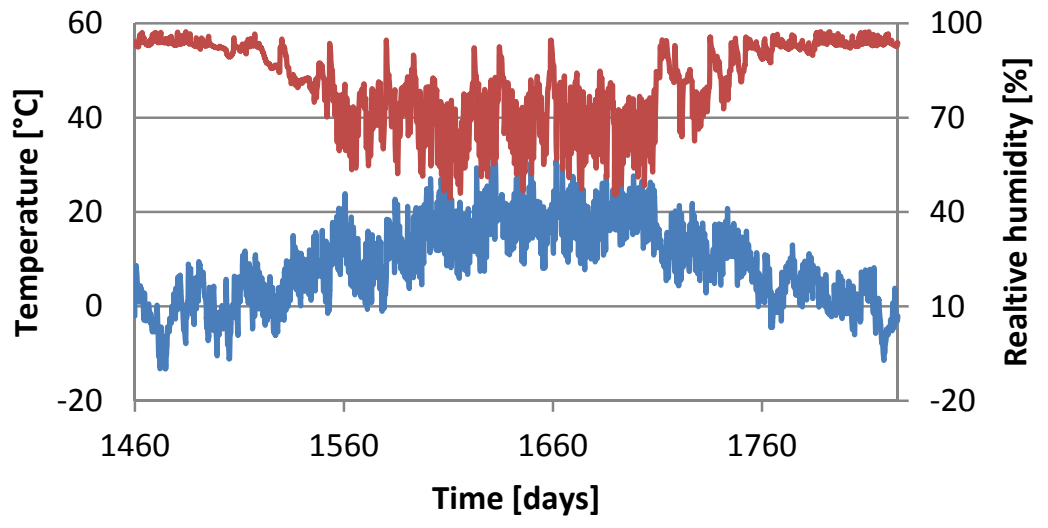

\section{- Temperature Relative humidity}

Figure 7: Time development of temperature and relative humidity in the AAC block.

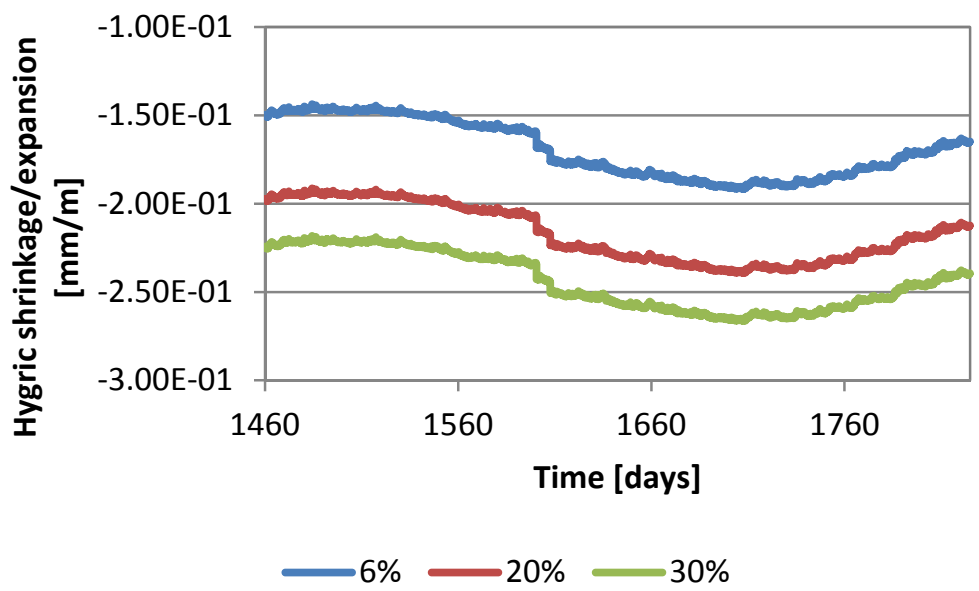

Figure 8: Hygric shrinkage/expansion of studied AAC block with different initial conditions. 
Each numerical simulation took 5 years; the results are given for the last year of the simulation. In Fig. 7 there is a time development of temperature and moisture content in the material $5 \mathrm{~mm}$ under the surface layer. These time developments were practically identical in all three simulations, therefore only one figure is presented. The time development of moisture content was used as the input parameter for calculation of hygric shrinkage/expansion. Fig. 8 shows the total hygric shrinkage/expansion related to the initial state of the material. The curves are very similar to each other; the only difference is caused by the initial state of the material. The driest state exhibits the smallest shrinkage and vice versa. The maximum shrinkage of $0.265 \mathrm{~mm} / \mathrm{m}$ was achieved in the summer months.

\section{Conclusions}

In this paper a numerical simulation of drying shrinkage was presented. For that purpose, a mathematical model was developed, which combined a coupled hygrothermal numerical model with a mechanical model in order to describe the evolution of hygric expansion/shrinkage of the AAC block.

As is obvious from the presented results, the best performance of AAC was achieved with the lowest initial moisture content of the block. To avoid mechanical damage caused by drying shrinkage, it is strongly recommended to use as much dry AAC as possible.

Further research should be aimed at an improvement of the used mathematical model. For example the cross effects between the hygrothermal and mechanical model should be taken into account and a complex hygrothermo-mechanical model should be employed. As this paper investigates hygric changes only, it would also be valuable to involve thermal changes as well, in order to provide the designers with a more complex tool for the assessment of volumetric changes of AAC in real constructions.

\section{Acknowledgement}

This research has been supported by the Czech Science Foundation, under project No P105/12/G059.

\section{References}

[1] Ramamurthy K., Narayanan, N., Influence of composition and curing on drying shrinkage of aerated concrete, Materials and Structures/Metériaux et Constructions, Vol. 33, pp. 243-250, 2000.

[2] CSN EN 680, Determination of the drying shrinkage of autoclaved aerated concrete, Prague: CNI, 2006.

[3] Jerman, M., Výborný, J., Černý R., Drying shrinkage of autoclaved aerated concrete, Thermophysics 2011, Brno: University of Technology, pp. 72-76, 2011. 
[4] Kočí, V., Maděra, J., Černý, R., Influence of characteristic types of thermal insulation on energy savings of AAC-based building envelope: a comparison, WIT Transactions on Ecology and the Environment, vol. IV, no. 165, pp. 263-274, 2012.

[5] Kočí, V., Maděra, J., Černý, R., Exterior thermal insulation systems for AAC building envelopes: computational analysis aimed at increasing service life, Energy and Buildings, vol. 47, no. 1, pp. 84-90, 2012.

[6] $\mathrm{H}+\mathrm{H}-$ technical parameters of products, URL: http://www.hplush.cz/c/document_library/get_file?folderId=528926\&nam $\mathrm{e}=$ DLFE-11218.pdf

[7] Jerman, M., Keppert, M., Výborný, J., Černý, R., Moisture and heat transport and storage characteristics of two commercial autoclaved aerated concrete, Cement Wapno Beton, 16/78(1), pp. 18-29, 2011.

[8] ČSN EN 13009, Hygrothermal performance of building materials and products - Determination of hygric expansion coefficient, Prague: CNI, 2001.

[9] Künzel, H. M., Simultaneous Heat and Moisture Transport in Building Components, PhD Thesis, IRB Verlag Stuttgart, 1995.

[10] Černý R., Complex System of Methods for Directed Design and Assessment of Functional Properties of Building Materials: Assessment and Synthesis of Analytical Data and Construction of the System. CTU: Prague, pp. 192-201. 2010.

[11] Kruis, J., Koudelka, T. \& Krejčí, T., Efficient computer implementation of coupled hydro-thermo-mechanical analysis. Mathematics and Computers in Simulation, 80, pp. 1578-1588, 2010.

[12] Kočí, J., Kočí, V., Duurana, K., Maděra, J., Černý, R., Determination of Moisture-Dependent Moisture Diffusivity Using Smoothed Experimental Data, 11th International Conference on Numerical Analysis and Applied Mathematics 2013, New York: American Institute of Physics, pp. 2038-2041, 2013. 